\title{
PEMANFAATAN SIKLUS PEMBUANGAN AIR TERHADAP SISTEM DRAINASE PERUMAHAN KOTA
}

\author{
Azwarman \\ Teknik Sipil, Fakultas Teknik Universitas Batanghari Jambi
}

\begin{abstract}
Abstrak
Banjir sebagai salah satu masalah besar di Kota Jambi biasanya dikendalikan dengan mengatur drainase dan sistem drainase. Ada baiknya menerapkan bagaimana pengendalian banjir tersebut dapat memberi manfaat akan kelangkaan air di saat kemarau. Pemanfaatan air dengan cara menyimpan air sebagai pengendalian kelangkaan air disaat musim kemarau sangat penting. Pengaturan sistem pemanfaatan air dapat diterapkan terhadap pengelolaan air yang diterima dan dibuang oleh banyaknya bangunan yang berada di lahan kosong saat ini. Permasalahan tersebut dapat kita lihat dari pengaturan sistem pipa saluran pada bangunan di Kota Jambi kurang terkoordinasi dan kurang efisien. Mengatur siklus air yang mengalir terhadap pipa saluran pada bangunan yang tidak dimanfaatkan dengan maksimal. Penelitian dilakukan di Kota Jambi, mengambil studi kasus perumahan dengan melakukan rekayasa ke sistem drainase perumahan sehingga desain baru mulai muncul. Analisisnya berupa observasi lapangan dan analisis data. Lokasi tempat tinggal ini terletak di Paalmerah Kota Jambi dengan tipe bangunan 78/105 dan ada 23 unit bangunan dengan fasilitas taman dan keamanan. Dimensi sumur dan waduk penyerapan dapat ditentukan untuk perumahan Jatayu. Dimensi penyerapan adalah 1,60 m sedangkan untuk dimensi bak penampung adalah penampang persegi panjang dengan ukuran $2 \mathrm{~m}$ x $1,5 \mathrm{~m}$ x 1,5 m.

Kata kunci : curah hujan, konservasi air, efisiensi
\end{abstract}

\begin{abstract}
Flooding as one of the big problems in Jambi City can be overcome by arranging drainage and drainage system for flood control. However, excess water during floods and used in anticipation of water shortages during the dry season has not been widely studied. The basic principle of water utilization is the engineering into a system of absorption wells or also known as water conservation which aims to prevent or minimize the lost water as the flow of the surface and store it as much as possible into the earth. The study was conducted in Jambi City, taking a case study of housing by conducting engineering to the housing drainage system so that new designs are emerging. The analysis is in the form of field observation and data analysis. This residential location is located in Paalmerah Village with 78/105 building type and there are 23 units of buildings with garden facilities and security. The results show that based on the intensity of rainfall, the dimensions of absorption wells and reservoirs can be determined for Jatayu housing. The dimension of absorption well is with the diameter of circle $1 \mathrm{~m}$ and height $1.89 \mathrm{~m}$ while for the storage tub dimension is rectangular cross section with size $2 m \times 1.5$ $m \times 1.5 \mathrm{~m}$.
\end{abstract}

Keywords: rainfall, water conservation, efficiency

\section{PENDAHULUAN}

Banjir sebagai salah satu masalah besar di Kota Jambi biasanya diatasi dengan mengatur drainase dan sistem drainase untuk pengendalian banjir. Namun sebaliknya, kekurangan serta kelangkaan air saat musim kemarau kurang 
diantisipasi seperti mengatasi banjir. Pengendalian banjir tersebut mestinya tidak hanya bagaimana mengatasi kelebihan air saja, namun mestinya dapat memberi manfaat disaat terjadinya kelangkaan air.

Manusia tidak akan lepas dari kebutuhan air, untuk menjalankan berbagai macam bentuk kegiatan untuk kelangsungan hidupnya. Mulai dari kebutuhan terhadap pangan, sampai dengan pemanfaatan sebagai pengamanan safety menggunakan air, dalam pengembangan produktifitas air dibutuhkan sistem atau pola yang efektif agar daya guna air menjadi maksimal. Pengaturan sistem pemanfaatan air dapat diterapkan terhadap pengelolaan air yang diterima dan dibuang oleh banyaknya bangunan yang berada di lahan kosong saat ini. Permasalahan tersebut dapat dilihat dari pengaturan sistem pipa saluran pada bangunan di Kota Jambi kurang terkoordinasi dan kurang efisien. Mengatur siklus air yang mengalir melalui pipa saluran pada bangunan yang tidak dimanfaatkan dengan maksimal.

Penelitian ini bertujuan untuk :

1. Peningkatan kualitas terhadap penggunaan air saluran drainase perumahan.

2. Menyadarkan masyarakat perumahan agar peduli terhadap sistem drainase yang sering bermasalah sehingga terjadi banjir di lingkungan perumahan.

3. Menghasilkan desain yang bisa menjadi pedoman masyarakat guna memaanfaatkan sistim drainase yang telah ada.

Prinsip dasar pemanfaatan air tersebut bisa di rekayasa menjadi sistem sumur resapan disebut juga sebagai konservasi air adalah mencegah atau meminimalkan air yang hilang sebagai aliran permukaan dan menyimpannya semaksimal mungkin ke dalam tubuh bumi. Atas dasar prinsip ini maka curah hujan yang berlebihan pada musim hujan tidak dibiarkan mengalir ke laut tetapi di tampung dalam suatu wadah yang memungkinkan air kembali meresap ke dalam tanah groundwater recharge melalui pemanfaatan air hujan dengan cara membuat kolam pengumpul air hujan, sumur resapan dangkal, sumur resapan dalam dan lubang resapan biopori. (Peraturan Menteri Negara Lingkungan Hidup. 2009).

\section{Sumur Resapan (Infiltration Wells)}

Sumur resapan merupakan sumur atau lubang pada permukaan tanah yang dibuat untuk menampung air hujan agar dapat meresap ke dalam tanah ( Kusnaedi, 2011). Sumur resapan ini kebalikan dari sumur air minum. Sumur resapan merupakan lubang untuk memasukkan air ke dalam tanah, sedangkan sumur air minum berfungsi untuk menaikkan air tanah ke permukaan. Dengan demikian, konstruksi dan kedalamannya berbeda. Sumur resapan digali dengan kedalaman di atas muka air tanah, sedangkan sumur air minum digali lebih dalam lagi atau di bawah muka air tanah. Penerapan sumur resapan sangat dianjurkan dalam kehidupan sehari - hari. Beberapa fungsi sumur resapan adalah sebagai berikut :

a) Pengendali banjir (Flood control)

b) Konservasi air tanah

c) Menekan laju erosi

\section{Penampungan Air (Water Reservoirs)}

Bak penampung / reservoir atau lebih tepatnya Ground Reservoir berfungsi sebagai penampung/penyimpan air, baik dari hasil olahan (jika menggunakan pengolahan) maupun langsung dari sumber mata air. Selain itu, bak penampung berfungsi untuk mengatasi masalah naik turunnya kebutuhan air dan merupakan 
bagian dari pengelolaan distribusi air di masyarakat. Bak penampung juga dapat digunakan untuk pengambilan air langsung (seperti hidran umum). Bak penampung juga dapat memperbaiki mutu air melalui proses pengendapan. Bangunan bak penampung dapat berupa beton cor, pasangan bata, atau bak plastik (fiber) yang disesuaikan dengan kebutuhan dan kondisi. Bak penampung harus kedap air dan tidak mudah bocor.

\section{Penyaring Lemak (Grease Trap)}

Penyaring lemak yang biasa disebut grease trap memiliki fungsi untuk menyaring lemak dari hasil cucian piring dan wadah bekas dapur. Grease Trap adalah alat perangkap grease atau minyak dan oli. Alat ini membantu untuk memisahkan minyak dari air, sehingga minyak tidak menggumpal dan membeku di pipa pembuangan dan membuat pipa tersumbat. Terbuat dari pasangan bata maupun stainless steel sehingga aman dari korosi.

\section{METODOLOGI}

\section{Gambaran Umum}

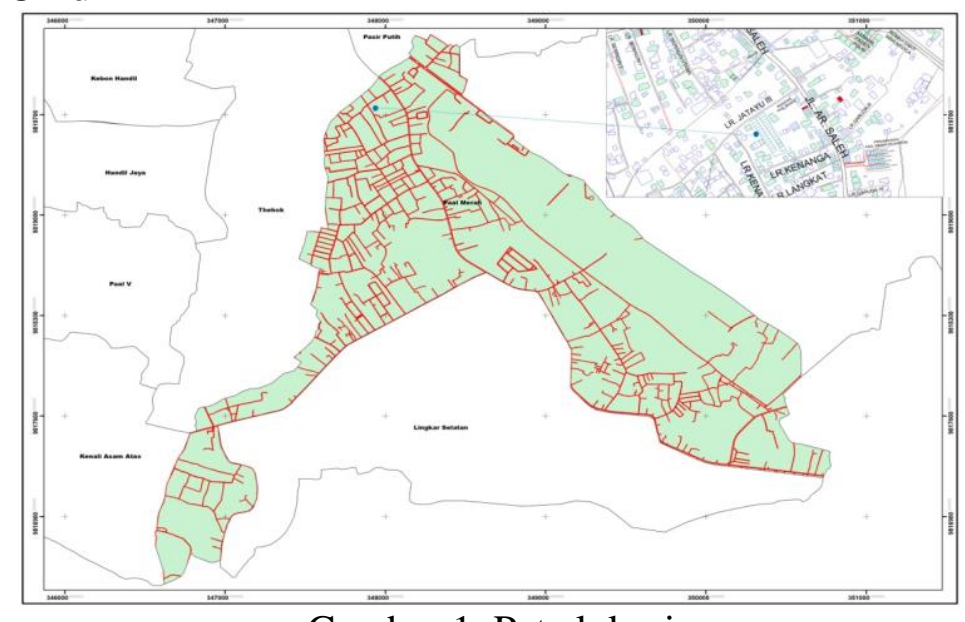

Gambar 1. Peta lokasi

Sumber : Badan Perencanaan Pembangunan Daerah dan penambahan detail menggunakan software MapInfo v.7.0

Penelitian ini dilaksanakan di Kota Jambi, mengambil studi kasus perumahan dengan mengadakan perekayasaan terhadap sistem drainase perumahan tersebut sehingga muncul desain baru. Analisisnya berupa observasi lapangan dan pengolahan data. Lokasi perumahan ini terletak di Kelurahan Paalmerah dengan tipe bangunan 78/105 dan terdapat 23 unit bangunan dengan memiliki fasilitas taman dan kemanan. Lahan kosong ini baru dibangun 6 unit rumah dan berupa pagar. Adanya lahan kosong yang belum dibangun dapat menjadi studi rekayasa konsep siklus air yang akan ditinjau untuk makalah ini. Pada umumnya saluran pembuangan perumahan hanya terbuang pada drainase perumahan dan di buang kembali ke drainase primer lalu kembali ke sungai. Pada konsep makalah ini bagaimana mengatur air buangan dapat dimanfaatkan untuk irigasi dan pemanfaatan fitur air sebagai keamanan kebakaran.

\section{HASIL DAN PEMBAHASAN}

Sistem Drainase Perumahan

Sistem drainase berfungsi untuk mengatur siklus air buangan dengan pemanfaatan maksimal. Berikut Tampak samping pengaturan sistem drainase perumahan yang akan diterapkan : 


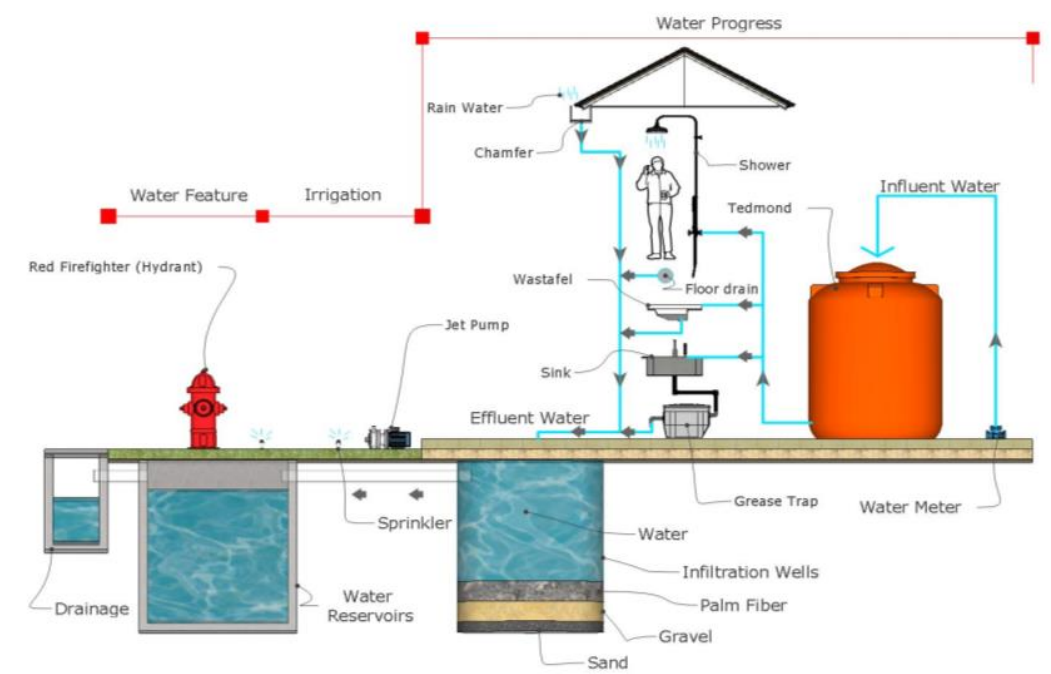

Gambar 2. Tampak samping pemanfaatan siklus air perumahan Sumber : Penggambaran menggunakan software sketchup

\section{Analisis dan Perhitungan}

Menerapkan konsep yang terlebih dahulu telah dipelajari dengan baik fungsi dari beberapa komponen yang menyangkut dalam sistem siklus air yang akan dibuat. Setelah mengetahui definisi dari komponen yang bersangkutan, perlu dilakukan analisis dan perhitungan untuk dapat mengetahui dimensi dan volume dari sumur resapan dan bak penampungan. Adapun analisis dan perhitungan yang akan dilakukan adalah sebagai berikut:

\section{Menghitung Debit}

Salah satu metode yang umum digunakan untuk memperkirakan laju aliran puncak (debit banjir atau debit rencana) yaitu Metode Rasional USSCS (1973). Metode ini digunakan untuk daerah yang luas pengalirannya kurang dari 300 ha (Goldman et.al., 1986, dalam Suripin, 2004). Debit dihitung menggunakan rumus rasional dan nilai intensitas diambil dari tugas akhir mahasiswa UNBARI dengan nilai intensitas curah hujan periode ulang 10 tahun yaitu; 71,193mm/jam. Berikut langkah - langkah mencari nilai debit rencana :

Perumahan ini memiliki luas area $4022 \mathrm{~m}^{2}$ atau 0.402 ha. Untuk mencari luas area menggunakan software Autocad v.2007 dan sketchup v.2015.

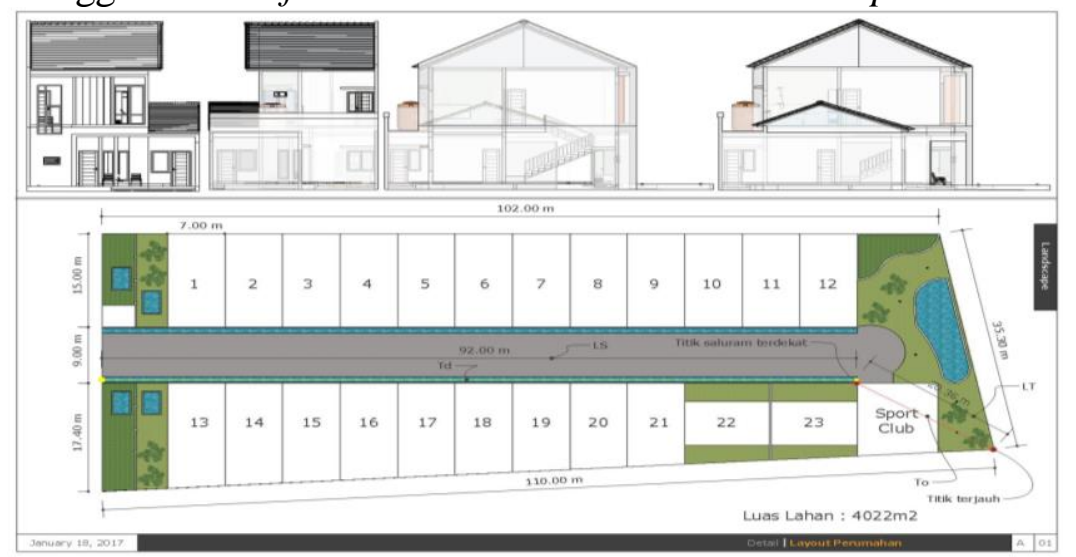

Gambar 3. Luas Area Perumahan

Sumber : Penggambaran software Autocad dan Sketchup. 


$$
\begin{aligned}
& \mathrm{To}=\frac{0,0195}{60}\left(\frac{\mathrm{LT}}{\sqrt{\mathrm{So}}}\right)^{0,77} \\
& \mathrm{To}=\frac{0,0195}{60}\left(\frac{20,36}{\sqrt{0,002}}\right)^{0,77}=0,036 \\
& \mathrm{Td}=\frac{\mathrm{LS}}{3600 \times \mathrm{V}} \\
& \mathrm{Td}=\frac{92}{3600 \times 0,4}=0,064 \\
& \mathrm{Tc}=\mathrm{To}+\mathrm{Td} \\
& \mathrm{Tc}=0.036+0.064=0,1 \\
& \mathrm{Cs}=\frac{2 \mathrm{Tc}}{2 \mathrm{Tc}+\mathrm{Td}} \\
& \mathrm{Cs}=\frac{2 \times 0,1}{2(0,1+0,064)}=0,61
\end{aligned}
$$

Debit rencana total area perumahan tanpa sumur resapan $\mathrm{Q}_{\mathrm{T}}=0,00278 . \mathrm{C} \cdot \mathrm{C}_{\mathrm{s}} . \mathrm{I} \cdot \mathrm{A}$ $\mathrm{Q}_{\mathrm{T}}=0,00278 \times 0,7 \times 0,61 \times 71,193 \times 0.402=0,03 \mathrm{~m}^{3} / \mathrm{detik}$

Debit rencana yang dihasilkan satu perumahan tanpa sumur resapan $\mathrm{Q}_{\mathrm{T}}=0,00278 \times 0,7 \times 0,61 \times 71,193 \times 0.0105=0.00088 \mathrm{~m}^{3} /$ detik

Dimana : $\quad \mathrm{Q}_{\mathrm{T}}=$ debit rencana $\left(\mathrm{m}^{3} /\right.$ detik).

$\mathrm{C}_{\mathrm{s}}=$ koefisien tampungan.

$\mathrm{I}=$ intensitas curah hujan $(\mathrm{mm} / \mathrm{jam})$.

$\mathrm{A}=$ luas catchment area $\left(\mathrm{Ha}^{2}\right)$.

$\mathrm{Td}=$ Waktu pengaliran air yang mengalir di dalam saluran sampai titik yang ditinjau (conduit time) dalam menit.

To = waktu pengaliran air yang mengalir di atas permukaan lahan menuju saluran (inlet time) dalam menit.

$\mathrm{Tc}=$ Waktu konsentrasi(jam).

\section{Mencari Luas Penampang Saluran Drainase}

Penampang saluran drainase perumahan direncanakan menggunakan penampang persegi panjang. Untuk mencari dimensi bentuk penampang menggunakan software Hec-ras v. 4.1 dengan memasukkan nilai debit dari hasil perhitungan dan koefisien manning.

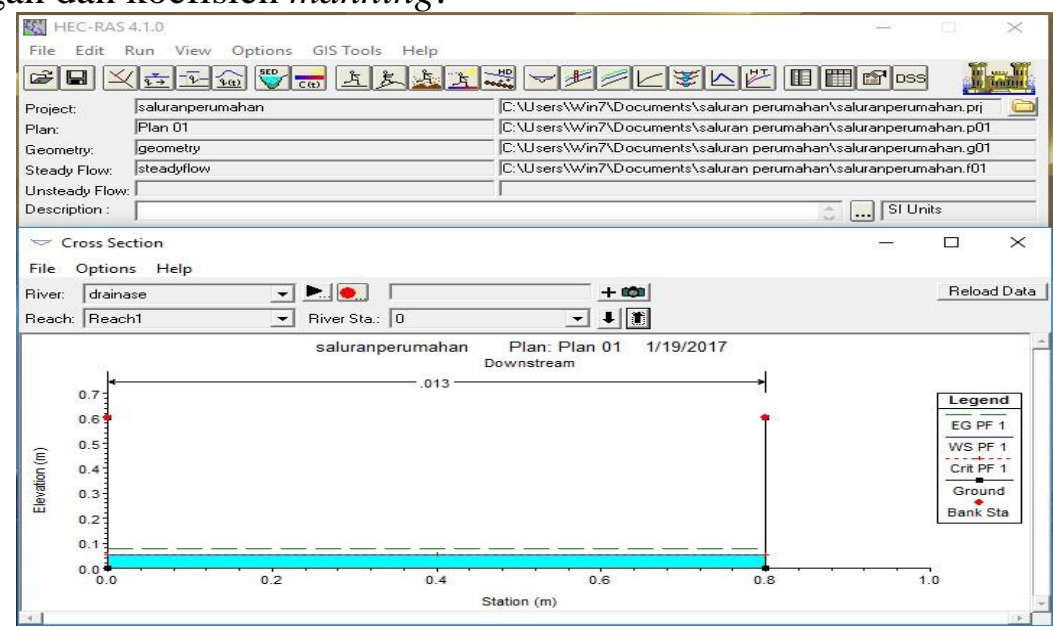

Gambar 4. Penampang saluran pada titik nol

Sumber : Hasil perhitungan software Hec-ras v.4.1 


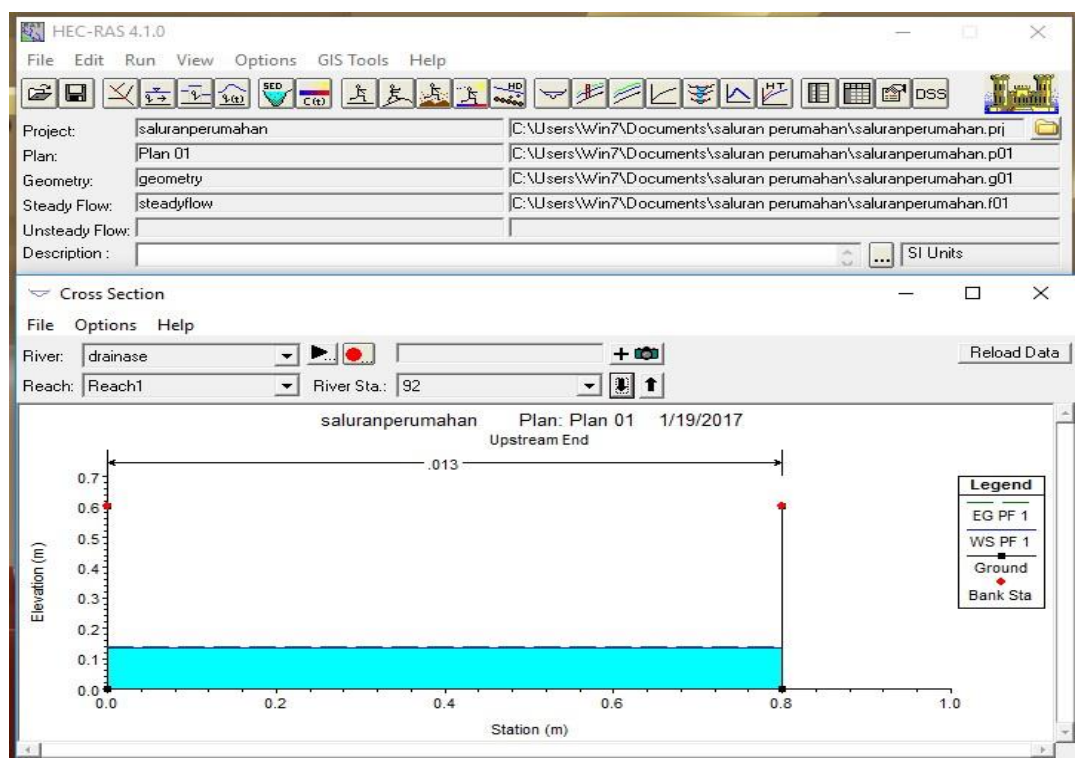

Gambar 5. Penampang saluran pada titik ahkir

Sumber : Hasil perhitungan software Hec-ras v.4.1

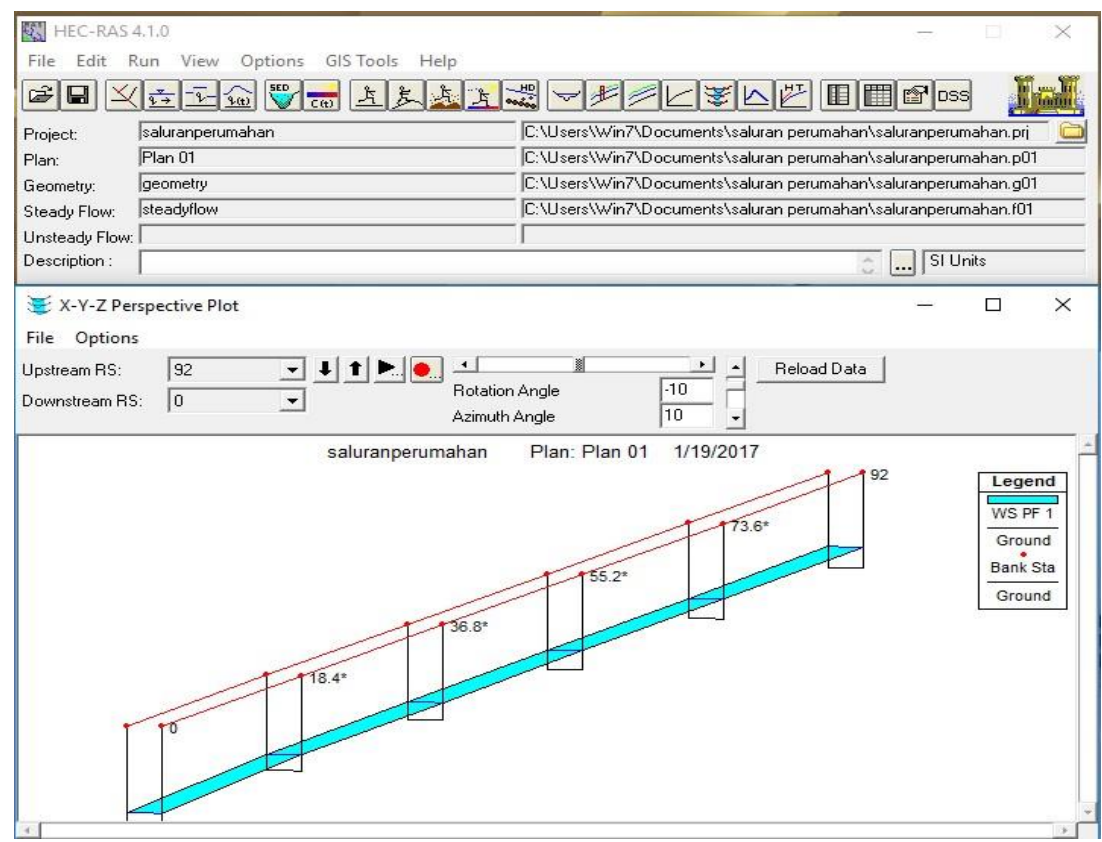

Gambar 6. Penampang saluran view 3d

Sumber : Hasil perhitungan software Hec-ras v.4.1

\section{Dimensi Sumur Resapan}

Dengan Analisis teoritis menggunakan formula Sunjoto (2011) untuk dimensi sumur resapan, maka dilakukan perhitungan sebagai berikut :

Diketahui data-data perumahan jatayu :

a) Luas total perumahan $(\mathrm{A})=0.402 \mathrm{ha}$

b) Luas 1 unit perumahan $=105 \mathrm{~m}^{2}=0.0105 \mathrm{ha}$

c) Luas atap 1 unit rumah $=56 \mathrm{~m}^{2}=0.0056 \mathrm{ha}$

d) Intensitas curah hujan $=71,193 \mathrm{~mm} / \mathrm{jam}$ durasi hujan dominan $(\mathrm{t})=$ $7200 d e t i k$.

e) koefisien permeabilitas $(\mathrm{K})=2 \times 10^{-4} \mathrm{~m} /$ detik (tanah kelanauan)

$\mathrm{Q}_{\mathrm{i}}=0,00278 \times \mathrm{C}_{\text {atap }} \times \mathrm{I} \times \mathrm{A}$ 
$\mathrm{Q}_{\mathrm{i}}=0,00278 \times 0,95 \times 71,193 \times 0.0056=1.05 \times 10^{-3} \mathrm{~m}^{3} /$ detik

Jenis sumur kosong tampang lingkaran dengan diameter sumur rencana :

$(\mathrm{D})=1 \mathrm{~m}$ dan $\mathrm{F}=5.5 \mathrm{R}=5.5 \times(0.5)=2.75 \mathrm{~m}$

Maka, tinggi sumur resapan adalah :

$\mathrm{H}=\frac{Q i}{F K}\left(1-e_{\pi R^{2}}^{-F K T}\right)=\frac{1.05 \times 10^{-1}}{2.75 .2 .10^{-4}}\left(1-e^{-\frac{2.75 .2 .10^{-4} .7200}{\pi 0,5^{2}}}\right)=1.89 \mathrm{~m}$

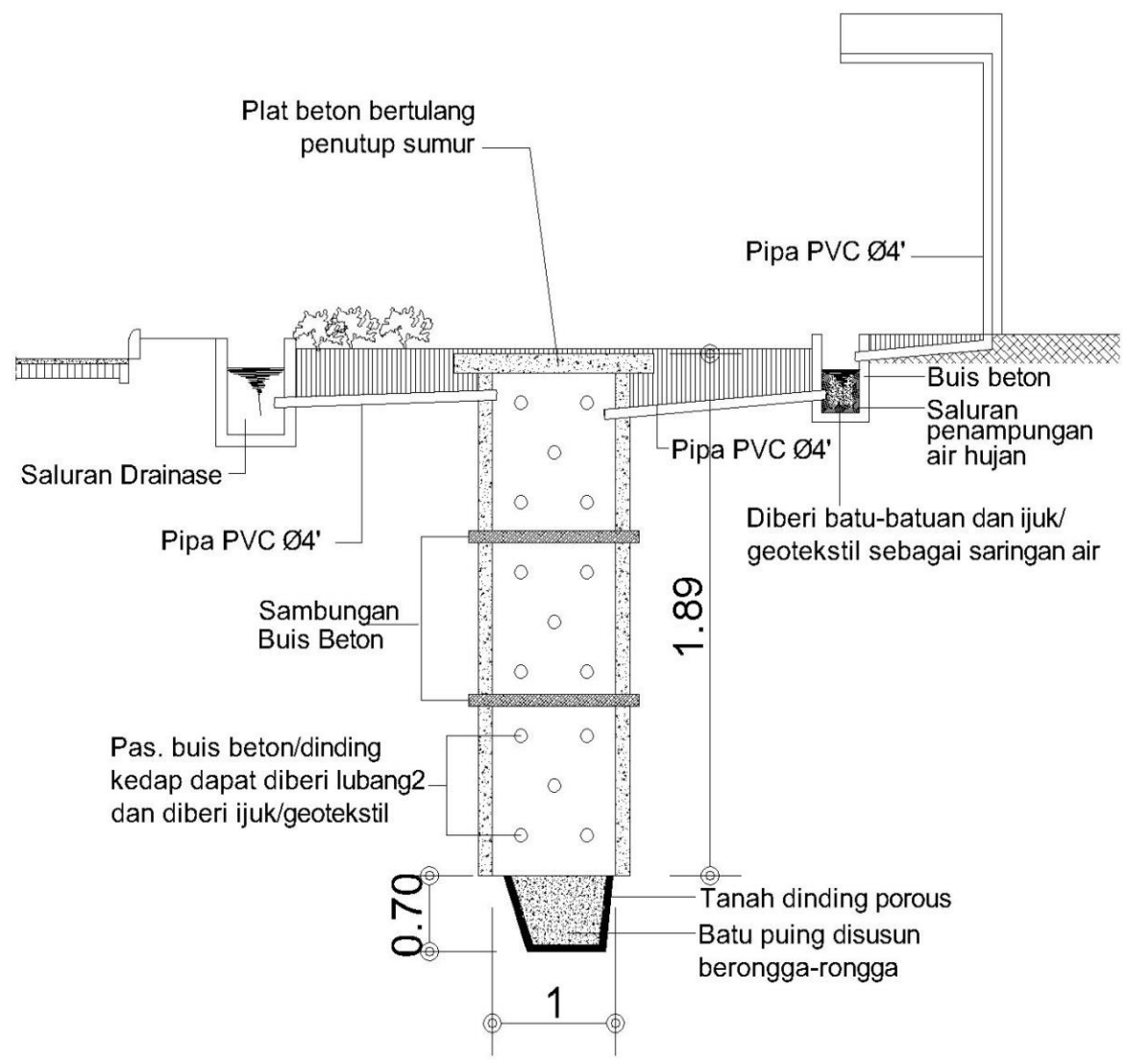

Gambar 7. Penampang sumur resapan

Sumber : Hasil penggambaran software Autocad 2007

\section{Dimensi Bak Penampungan}

Berdasarkan SNI 03-7065-2005, penggunaan air pada tempat tinggal per orang yaitu 120 liter/hari. Pada perumahan type 105 diasumsikan memiliki 5 penghuni rumah. Maka air yang terbuang dalam satu hari adalah :

1 orang $=120$ liter

5 orang $=120$ liter $\times 5=600$ liter $/$ hari.

Penggunaan wastafel $=10$ liter/pemakaian

Diasumsikan per orang menggunakan wastafel 5 kali pemakaian. Maka, total pemakaian 25 kali dengan penggunaan air sebanyak $=250$ liter .

Penggunaan sink(cuci piring) $=25$ liter/pemakaian

Diasumsikan pemakaian untuk mencuci piring 3kali, jadi total penggunaan air cuci piring sebanyak $=75$ liter

Penggunaan shower mandi $=42$ liter/pemakaian

1hari 3 kali pemakaian /orang, total penghuni 5 orang. Maka total pemakaian 15 kali dengan penggunaan air $=15 \times 42$ liter $=630$ liter.

Penggunaan mencuci pakaian $=9,5$ liter/cycle 
dalam satu hari diasumsikan per orang mencuci pakaian 4 pakaian, total pakaian yang dicuci dalam satu rumah $5 \times 4=20$ pakaian. Jadi total penggunaan $=20 \mathrm{x}$ 9,5liter $=190$ liter.

Total keseluruhan adalah :

$600+250+75+42+630+190=1712$ liter/hari.

Untuk perencanaan bak penampungan $2 \mathrm{~m} \times 1.5 \mathrm{~m} \times 1.5 \mathrm{~m}=4.5 \mathrm{~m}^{3}=4500$ liter. Bak penampungan dapat menampung air satu unit rumah dalam keadaan penuh selama 2 hari setengah dan sisanya ke drainase.

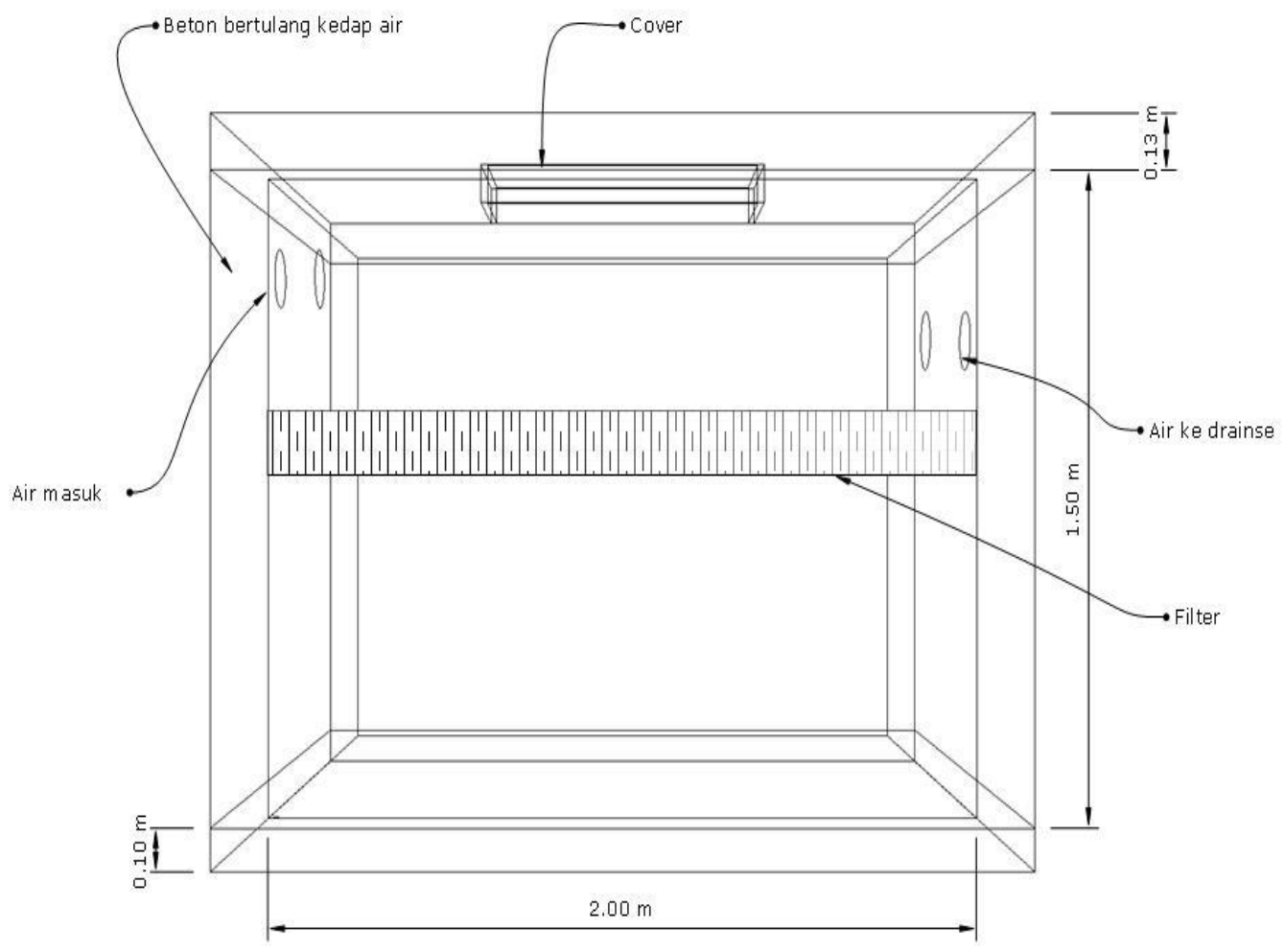

Gambar 8. Penampang Bak Penampungan

Sumber : Hasil penggambaran software Autocad 2007

\section{KESIMPULAN}

1. Berdasarkan intensitas curah hujan, maka dimensi sumur resapan dan bak penampungan dapat ditentukan untuk Perumahan Jatayu. Adapun dimensi sumur resapan adalah dengan diameter lingkaran $1 \mathrm{~m}$ dan tinggi $1,89 \mathrm{~m}$ sedangkan untuk dimensi bak penampungan adalah penampang persegi panjang dengan ukuran $2 \mathrm{~m}$ x 1,5 m x 1,5 m.

2. Melakukan konsep pemanfaatan air di lingkungan perumahan ini sangat efektif untuk memperbaiki keadaan air tanah dan mengurangi debit banjir serta dapat dimanfaatkan untuk keperluan lain seperti hydrant sebagai sarana pemadam kebakaran pada suatu lahan perumahan.

3. Dengan mengendalikan banjir juga dapat mengendalikan kelangkaan air disaat musim kemarau dikarenakan telah merencanakan bak penampungan. Dengan buangan air yang dilakukan setiap unit perumahan ditampung. 


\section{SARAN}

Sebaiknya penelitian dilakukan lebih detail untuk kebutuhan buangan air, dikarenakan masing masing manusia dengan perbedaan gender dan usia berbeda pemakaian airnya.

\section{DAFTAR PUSTAKA}

Badan Meteorolgi Klimatologi dan Geofisika, (BMKG) Sultan Thaha Kota Jambi.

Chow V. T. 1964 .Handbook of Applied Hydrology, McGraw-Hill, Inc. New York.

Dinas Pekerjaan Umum Kota Jambi, (Bidang Pengairan dan Drainase), 2016.

Gunadharma, 1997, Drainase Perkotaan. Jakarta.

H.R. Mulyanto, 2012, Penataan Drainase Perkotaan. Semarang.

Kusnaedi, 2011, Sumur Resapan, Penebar Swadaya. Bogor

Suripin, 2004, Sistem Drainase Perkotaan Yang Berkelanjutan, ANDI. Yogyakarta

Wesli. 2008. Drainase Perkotaan, Edisi Pertama - Yogyakarta; Graha Ilmu. 